\title{
O LUGAR DA ARQUITETURA ${ }^{1}$
}

Roberto SCHWARZ ${ }^{2}$

- PALAVRAS-CHAVE: Arquitetura; modernidade; pós-modernidade; projeto funcionalista; vanguarda.

\section{Cara Otília:}

Somos amigos há muitos anos, e há muitos anos sou seu leitor atento. De modo que digo sem nenhum medo de errar que o seu trabalho intelectual chegou num ponto ótimo.

Você publicou há pouco um livro sobre Mário Pedrosa que é realmente de primeira, cheio de observações que interessam à história não só de nossas artes plásticas, como de nossa literatura e vida política (Máno Pedrosa: itinerário crítico. São Paulo: Scritta, 1991). É um trabalho que convida a sair da rotina e arriscar conexões entre domínios da vida que se costumam estudar em separado.

Acompanhando o percurso de um homem ligado ao mesmo tempo à vanguarda artística e à vanguarda política, você historia e analisa os acertos e os desencontros próprios a essa combinação, que para muitos de nós representou o ideal. Ao longo da vida tão movimentada e internacional de Mário Pedrosa, vão se aliando e desentendendo o socialismo, a arte social de Kathe Kollwitz nos anos 30, a luta anti-stalinista, o abstracionismo nos anos 50 e o megaexperimento modernista que é a construção de Brasília.

Para o meu gosto, à parte as muitas ligações apontadas e os acertos de caracterização, o achado do livro está na sua linha central. Com toda razão, você sublinha a unidade do impulso utópico, o qual levava o intelectual a ser revolucionário tanto nas artes quanto em política, a ponto de imaginar que a realização de projetos

\footnotetext{
1 Argüição do Concurso de Livre-Docência de Otilia B. F. Arantes, na Faculdade de Filosofia, Letras e Ciências Humanas - USP.

2 Ensaísta e crítico, autor de O pai de família e Machado de Assis - Um mestre na periferia do capitalismo.
} 
caros à vanguarda artística só podia ser indício de algo paralelo no campo social. Daí o entusiasmo que levou Pedrosa a se tornar por um momento uma espécie de ideólogo de Brasília.

Pois bem, chegada aqui, você teve o bom senso (e a ousadia) de considerar que esta Brasília, que realizava o programa de artistas tão indiscutivelmente avançados como Niemeyer e Lucio Costa, não dizia respeito somente ao mundo dos arquitetos. Ela era a mesma que, do ponto de vista da crítica social, representara um aprofundamento do caráter autoritário e predatório da modernização brasileira, em linha com a tendência que em seguida levaria ao regime militar.

Noutras palavras, a realização mais sensacional e abrangente do programa histórico das vanguardas artísticas incluía entre as suas virtualidades o servir de álibi a um processo de modernização passavelmente sinistro, em cuja esteira ainda nos encontramos, e ao qual aquela realização em fim de contas se integra bem, sem dissonância notável.

A revolução nas formas arquitetônicas e urbanísticas não cumprira a sua promessa de revolucionar a vida para melhor. A Brasília da vida real, que não há porque passar por alto num debate estético que se preze, constitui uma verificação palpável do caráter iludido do vanguardismo abstrato - como aliás constataria o próprio Mário Pedrosa no último período de sua vida, quando afirma que a noção de vanguarda artística perdeu o fundamento. Noutras palavras, você soube reconhecer no percurso e sobretudo no impasse de um crítico o destino local, mas globalmente relevante, de uma das grandes aspirações deste século no âmbito da civilização burguesa.

Logo depois deste livro, você publicou outro, escrito a quatro mãos com Paulo Arantes, em que comenta e critica as duas conferências de Habermas em defesa do movimento modernista na arquitetura (Um ponto cego no projeto moderno de Jürgen Habermas. São Paulo: Brasiliense, 1992.) Este trabalho não é de leitura fácil, porque é superlotado de argumentos, e muito econômico e preciso na exposição.

O assunto está indicado no subtítulo: arquitetura e dimensão estética, depois das vanguardas. Trata-se da teoria da modernidade segundo o filósofo, bem como da situação da arquitetura contemporânea, confrontadas criticamente uma com a outra e tendo como fundo a "Teoria Estética" de Theodor Adorno. Indiretamente, está em jogo a própria situação atual da arte.

O tom é de discussão propriamente dita, sem ponto morto, sem temor à compartimentação acadêmica das especialidades, circulando com liberdade entre o argumento filosófico, a descrição de obras e a situação histórica. Tudo estritamente segundo as necessidades do objeto e do raciocínio, num clima de sobriedade e intensidadeintelectual que é raro. Penso não me enganar achando que há aí um padrão de prosa crítico-filosófica novo no país. Sem entrar na substância do livro, quero ainda chamar a atenção para o seu tópico final, intitulado "Um ponto de vista".

Depoís de haver discutido as razões da revalorização tardia da arquitetura moderna pelo filósofo, o ensaio salta para o Brasil, para a nossa experiência com o 
modernismo arquitetônico, a qual será chamada a testemunhar no capítulo. O passo à frente é grande e consiste em dar-se conta de que as teorias de um pensador, mesmo alemão, podem ser testadas sem despropósito pela experiência local, ou, mais grave ainda, que a reflexão sobre a experiência local pode fornecer um capítulo a um livro filosófico...

Há um avanço paralelo no argumento sobre o significado local da nova construção. A inadequação de origem está à vista de todos que tenham um vemiz materialista. De fato, "num meio acanhado como o nosso, onde está a base social e produtiva que daria sentido à racionalidade arquitetônica desejada pelos modernos?" Deste ângulo, na ausência de grande indústria, o Brasil não seria lugar apropriado para o essencial da nova arquitetura, cujos descaminhos locais seriam antes equívocos do que parte integral da linha histórica da arquitetura moderna. Ora, as suas reflexões vão em direção contrária a esta, cujo progressismo na verdade é conformista, pois se limita a denunciar e lamentar a falta das condições modernas no país.

O ponto de vista que você expõe é bem mais drástico, e sustenta que foi precisamente a ausência de uma sociedade industrial desenvolvida que permitiu a realização dos experimentos por assim dizer totais da arquitetura e do urbanismo novos, os quais não poderiam ocorrer senão nas condições autoritárias do Terceiro Mundo, por exemplo, na Índia ou no Brasil.

A reflexão nacionalmente engajada sobre os obstáculos locais à modernização (perspectiva tão incontornável quanto ideológica) cede o passo à reflexão teórica sobre o dinamismo modernizante global, tomada na sua feição efetiva, de que a teratologia terceiro-mundista faz parte. Assim, longe de ser um desvio sem significado, a combinação monstruosa e desconcertante de modernismo e miséria está na lógica do processo. Ela diz algo de essencial sobre a concepção de modernidade que animou a arquitetura deste século, bem como sobre a nossa idéia e a própria realidade da modernização.

Cada um a seu modo, os livros sobre Mário Pedrosa e sobre Habermas acompanham um movimento que, iniciado nos países do capitalismo maduro, a certa altura se transplanta e tem um capítulo brasileiro. Este, longe de ser uma variante folclórica, ensina algo de substantivo sobre o processo considerado no conjunto. $O$ mérito desprovincianizador desta estratégia expositiva é evidente, pois leva a encarar os fatos locais em termos não apenas nacionais, mas contemporâneos, e vice-versa, rompendo com a estreiteza de vistas do nacionalismo, sem no entanto desconhecer a realidade do âmbito a que este se refere. Nessas matérias, toda receita é um erro, mas nos dois trabalhos está dado este passo valioso, que acho que pode ser tomado como programa: os desenvolvimentos locais são vistos no bojo da história contemporânea, mas não como simples ilustração, em fim de contas redundante, e sim como momento verdadeiro e revelador do sentido geral da atualidade.

Bem, mas vamos então a seu livro novo, que você apresentou para esse concurso de livre-docência (O lugar da arquitetura depois dos modemos. São Paulo: Edusp, 
1993). Trata-se de um conjunto de ensaios que recapitula momentos significativos da arquitetura deste século, e também da correspondente doutrina e ideologia. $\mathrm{O}$ ângulo de observação é atual, quer dizer, tem como ponto de partida o abandono em nosso tempo do projeto funcionalista, trocado pela orientação, digamos, pós-moderna, ou, para usar o seu termo, pela arquitetura simulada.

A unidade dos ensaios é forte e ao longo deles vamos encontrando a formulação e a crise das idéias estéticas, e não só estéticas, de que todos nos alimentamos. A propósito, sempre me impressiona como a história contemporânea soa diferente segundo seja contada pelos historiadores da política, da economia ou da arte. O seu livro deve uma parte do interesse a esta diferença, à surpresa de ver o século apresentado do ângulo do debate arquitetônico. De fato, a linha evolutiva que você expõe convida à reflexão, à maneira do enredo de um romance: o que quer dizer este andamento das coisas?

Reduzida ao mínimo, a história seria a seguinte: o ânimo utópico da arquitetura, ou seja, os planos de redenção social através do novo arranjo do espaço habitado, na casa e sobretudo na cidade, deram no seu contrário. Em lugar da substância - que seria aquela transformação redentora - ficou um conjunto de normas de funcionalidade, que se mostraram funcionais sobretudo para o processo social e material da produção industrial. Passada a Segunda Guerra, as patologias urbanas desse novo tipo de sociedade se tornaram evidentes e inviabilizaram os sentimentos utópicos historicamente vinculados ao funcionalismo. Respondendo à morte deste, e aparentemente em oposição a ele, vão surgindo experiências que acabam se afunilando no clima pós-moderno. Você recusa esta oposição - o glosadíssimo antagonismo entre arquitetura moderna e pós-moderna - por considerá-la uma aparência encobrindo o essencial, que seria da ordem da continuidade. Este o ponto central de seu argumento, cujo caráter polêmico dispensa comentários.

Os passos da discussão são os seguintes: nos anos 20, quer dizer, na esteira da Revolução Russa, que colocara o socialismo na ordem do dia, diz Le Corbusier: "Arquitetura ou revolução. Podemos evitar a revolução". Você nota bem que a arquitetura aqui representa "uma alternativa à revolução, e não à sociedade convulsionada do entre-guerras. Logo adiante você lembra um passo da "Carta de Atenas" (Le Corbusier, 1933), segundo a qual a "cidade funcional" leva em conta quatro funções: morar, trabalhar, recrear-se, locomover-se. Como é fácil notar, tratava-se de uma reforma modernizante, universalista, caucionada pelo espírito da utopia. É um modelo único, que aspira à validade internacional e nivela as diferenças históricas. Observa você, concluindo, que essas abstrações urbanísticas especificam no plano que lhes é próprio as próprias abstrações operadas pelo capitalismo no plano das relações sociais e de produção. Ou ainda, usando a sua frase: "O mecanismo totalizador encarnado pela cidade era o palco desta abstração".

Assim, num primeiro momento, o "International Style" reveste de utopia as condições de generalidade requeridas pela expansão do capital. Esgotada a credibi- 
lidade desta promessa, surge a atual arquitetura do simulacro, do espetáculo, da multiplicação das imagens, escandalosamente oposta à sobriedade funcionalista e a seu ânimo de reforma. Você reage com bom senso e duvida da proclamada onipotência do simulacro, ou da volatilização da realidade operada pela presença generalizada da TV. Em lugar disso, você observa que, com a nova arquitetura, a cidade se torna ela mesma uma mídia, contribuindo por sua vez para a generalização do "efeito televisão". Guiada pela política cultural do Estado ou das grandes empresas, a arquitetura moderna vem a ser uma peça importante para o desenvolvimento da sociedade de consumo.

Assim, depois de interpretar as necessidades da industrialização capitalista, a arquitetura inventa as soluções necessárias ao aprofundamento do consumismo. Ou, como você queria demonstrar, funcionalismo e pós-modernismo são momentos sucessivos de uma mesma racionalidade social.

O resumo foi um pouco acelerado, mas espero que não tenha sido muito inexato e que permita algumas perguntas, com as quais termino.

De um modo geral, as suas exposições se completam pelo confronto entre idéia e resultado, entre o que um movimento promete e o que ele cumpre no seu desempenho efetivo. Embora esta ordem de confronto pertença ao programa e ao próprio receituário da dialética, são poucos os trabalhos bem-sucedidos nesta linha. Fazem parte do grupo estes seus estudos, em que o curso das promessas e dos resultados da arquitetura moderna compõe uma figura vasta e de fato impressionante. Dito isto, quero lembrar uma boa reflexão de Adorno, segundo a qual as ideologias não são mentirosas pela sua aspiração, mas pela afirmativa de que esta se tenha realizado. Qual o significado, qual o partido que a crítica de arte pode tirar deste espaço entre aspiração e realização, e sobretudo entre obra individual e tendência geral?

Neste sentido, como ficam as experiências modernistas de que mal ou bem se formaram as noções de beleza de nossa geração e da anterior, noções de que não saberia como abrir mão? Penso no impacto de revelações juvenis, como aquelas propiciadas - digamos - pelos móveis escandinavos, pela religião das tubulações aparentes, pela sobriedade do espaço moderno, pelo antiilusionismo do palco brechtiano etc. Foram absorvidas pela modernização, sem deixar resíduo crítico?

E como se liga ao destino da arquitetura a diferença tão tangível entre as casas modernas bonitas e as feias? Em que sentido as explicações que você dá poderiam incidir em nossa apreciação de obras-primas, por exemplo de Mies van der Rohe, ou de beldades como o Palácio do Itamaraty? O ângulo de análise teria de ser outro?

Minha cara Otília, quero cumprimentá-la calorosamente pelo bom trabalho.

SCHWARZ, R. The place of architecture. Trans/Form/Ação (São Paulo), v.18, p.9-13, 1995.

- KEYWORDS: Architecture; modernity; post-modernity; fonctionalist project; vanguard. 